\title{
Yapay Zekâ Rekabeti Bağlamında Çin'in Ontolojik Güvenlik Algısı
}

Semih ERDOĞDU ${ }^{1}$

$\ddot{0 z}$

Tarihsel olarak yaşadığı elim olaylar, Batı'nın tahayyülü ve geç modernleşme sürecinin de etkileri birlikte değerlendirildiğinde Çin'in kimlik algısında önemli izler bırakmıştır. Bu makale, ontolojik güvenlik arayışında olan Çin'in devlet rolüne odaklanmaktadır. Araştırmada ilk olarak, Çin'in, yapay zekâ teknolojisinde lider olma hedefine ulaşmak için gerçekleştirdiği eylemlerle, teknolojik üstünlük faktörüne dayalı olarak ABD'ye (Batı'ya) karşı 'meydan okuyucu' ve 'büyük bir ticaret ulusu' kimliğini güçlendirdiği ve başta ABD olmak üzere diğer devletlerle ilişki kurma rutinlerini geliştirerek ontolojik güvenlik arayışı davranışı sergilediği savunulmaktadır. Araştırmada ayrıca, Komünist Devrimle birlikte içeride başlatılan kalkınma hamlesi ve dişarıda yaşanan değişimleri takiben, Çin'in teknolojik gelişmeye dayanan büyük bir ticaret ulusu olarak nasıl ontolojik güvenlik arama çabasına giriştiği ortaya koyulmaktadır. Ontolojik güvenlik arayışı sürecini göstermek için yalnızca Çin'in yapay zekâ stratejisine odaklanılırken, Çin'in başka alanlardaki ontolojik güvenlik arayışlarını farklı şekillerde yönlendirdiği savlanmaktadır. Bu makalenin konusunu oluşturan küresel yapay zekâ rekabetinde Çin'in yerine ilişkin olarak, bu sürecin Çin'in başta ABD olmak üzere uluslararası ortamdaki diğer devletlere göre sahip olduğu konumu algılamasını güvence altına almak için hareket ettiği görülebilir.

Anahtar Kelimeler: Ontolojik Güvenlik, Ulusal Kimlik, Yapay Zekâ, Çin-ABD Rekabeti

China's Ontological Security Perception in the Context of Artificial Intelligence Competition

\begin{abstract}
When the sad events that it has experienced historically, the imagination of the West and the effects of the late modernization process are evaluated together, they have left important traces in China's identity perception. This article focuses on the state role of China, which seeks ontological security. In the research, firstly, with the actions taken by China to achieve its goal of being a leader in artificial intelligence technology, it has strengthened its identity as a 'challenger' and 'great trading nation' against the USA (West) based on the factor of technological superiority, and the USA in particular It is argued that it exhibits ontological security-seeking behavior by developing routines to establish relations with other states, such as The research also reveals how China, as a major trading nation based on technological development, has attempted to seek ontological security, following the development move initiated inside with the Communist Revolution and the changes experienced abroad. While focusing only on China's artificial intelligence strategy to show the process of seeking ontological security, it is argued that China directs the search for ontological security in other areas in different ways. Regarding the place of China in the global artificial intelligence competition, which is the subject of this article, it can be seen that this process acts to ensure that China perceives its position relative to other states in the international environment, especially the USA.
\end{abstract}

Keywords: Ontologial Security, National Identity, Artificial Intelligence, Sino-US Competition

\footnotetext{
${ }^{1}$ İstanbul Medeniyet Üniversitesi, Uluslararası İlişkiler Doktora Öğrencisi, semiherdogdu@ hotmail.com ORCID ID: https://orcid.org/0000-0001-5598-2484

Makale Geliş Tarihi: 11.07.2021, Makale Kabul Tarihi: 01.12.2021

ARAŞTIRMA MAKALESİ (Research Article)

*Bu makale intihal programında taranmış ve en az iki hakem incelemesinden geçmiştir. (This article has been scanned via a plagiarism software and reviewed by at least two referees).
}

Doi: 10.51524/uhusbad.969764 


\section{Giriș}

Tarihsel olarak yaşadığı elim olaylar, Batı'nın tahayyülü ve geç modernleşme sürecinin de etkileri birlikte değerlendirildiğinde Çin'in kimlik algısında önemli izler bırakmıştır. Komünist devrimle birlikte sahip olduğu potansiyel gücü kalkınma hamlesinde kullanmakta geri durmayan Çin, 1949'dan günümüze kadar bu gücünü aktif şekilde kullanmaya devam etmiştir. Bu bağlamda, Çin'in söz konusu kalkınma sürecinde teknolojik gelişmeyi ontolojik güvenlik faktörü olarak değerlendirdiğini söylemek mümkündür. Küresel siyasette güçlü bir konumda yer alarak ABD hegemonyasına karşı koyabilmek adına teknolojik üstünlüğe sahip olma isteği, tarihsel olarak Batı'nın sömürgeci geçmişine karşı duyulan öfke ve güvensizlik nedeniyle küresel siyasette güçlü konumda olma çabası, yapay zekâ teknolojisinde ilk yapan ve lider ülke olma gibi markalaşma çabalarına girerek küresel anlamda baskın güç olma isteği ve ABD'nin Güney Çin Denizi'ndeki agresif ve çevreleyici tutumuyla birlikte oluşan fiziki güvensizlik kaygılarıyla birlikte ABD'nin bölgedeki varlığının bir beka sorunu olarak algılanması Çin'in teknolojik gelişmeyi ontolojik güvenlik faktörü olarak öncüllemesinin sebepleri olarak değerlendirilebilir. Bu bağlamda söylenebilir ki, spesifik olarak yapay zekâ teknolojisinde ilk yapan ve lider ülke olma gibi kavramların vurgulandığ 1 girişimler ve söylemler Çin'in ontolojik güvenlik düşüncesi ile ilişkilendirilebilir.

Bu makale, ontolojik güvenlik arayışında olan Çin'in devlet rolüne odaklanmaktadır. Araştırmada ilk olarak, Çin'in, yapay zekâ teknolojisinde lider olma hedefine ulaşmak için gerçekleştirdiği eylemlerle, teknolojik üstünlük faktörüne dayalı olarak ABD'ye (Batı'ya) karşı 'meydan okuyucu' ve 'büyük bir ticaret ulusu' kimliğini güçlendirdiği ve başta $\mathrm{ABD}$ olmak üzere diğer devletlerle ilişki kurma rutinlerini geliştirerek ontolojik güvenlik arayışı davranışı sergilediği savunulmaktadır. Araştırmada ayrıca, Komünist Devrimle birlikte içeride başlatılan kalkınma hamlesi ve dışarıda yaşanan değişimleri takiben, Çin'in teknolojik gelişmeye dayanan büyük bir ticaret ulusu olarak nasıl ontolojik güvenlik arama çabasına giriştiği ortaya koyulmaktadır.

Bu makalede ontolojik güvenlik arayışı sürecini göstermek için yalnızca Çin'in yapay zekâ stratejisine odaklanılırken, Çin'in başka alanlardaki ontolojik güvenlik arayışlarını farklı şekillerde yönlendirdiği savlanmaktadır. Bu makalenin konusunu oluşturan küresel yapay zekâ rekabetinde Çin'in yerine ilişkin olarak, bu sürecin Çin'in başta ABD olmak üzere uluslararası ortamdaki diğer devletlere göre sahip olduğu konumu algılamasını güvence altına almak için hareket ettiği görülebilir. Aşağıda tartışılacağı üzere, Çin'in Öz-kimlik anlayışının güvenliği, bu kimliği güçlendiren eylemler ve Çin'in yapay zekâ özelinde teknolojik üstünlüğünün küresel olarak tanınması (ve dolayısıyla onaylanması) yoluyla aranır. Birçok akademisyen, genel olarak 'Çin İstisnacılığı' olarak tanımlanan, kapsayıcı ulusal Çin kimliği olarak görülebilecek olgu üzerine tartışma yürütmektedir. Bu kimlik, kendisini Asya'nın merkezi ve doğal lideri olarak gören, devletlerarası ilişkiler ve küresel liderliğe ilişkin batı normlarından ve ideallerinden önemli ölçüde farklı algılanan değerlere sahip bir Çin inşa ederek, ağırlıklı olarak Çin tarihine ve geleneksel değerlere atıfta bulunur (Callahan, 2012). Bu bağlamda makalenin son bölümünde, Çin'in ulusal kimliğinin doğasında var olan ontolojik güvenlik arayışı ve ontolojik güvenlik arayışında önemli bir faktör olarak Çin'in yapay zekâ stratejisi analiz edilecektir.

\section{Ontolojik Güvenlik Kavramı}

Uluslararası İlişkiler disiplininde yer alan yapısalcı bakış açısı kapsamında, devletlerin eylemlerini anlamak için ulusal kimlik ve kimlik inşalarının analizi gerçekleştirilir. Yapısalcı teoriye göre, kimlikler, devletlerin diğer devletlerle olan etkileşimi yoluyla inşa edilir. Burada devletten ve devlet ile etkileşimde bulunanların eylemlerini çevreleyen beklentileri davranışsal normlar dahilinde tanımlanır. Yapısal güç dengesi ya da varsayılan devlet güvenlik çıkarları tarafından tanımlanmak yerine, "güvenlik kavramları ... benliğin diğeriyle bilişsel olarak ne ölçüde ve nasıl tanımlandığına göre farklılık gösterir" (Wendt, 1992). Bu sosyal normların ve ulusal kimliklerin inşası süreklidir, çünkü süregelen etkileşimler, "belirli kimliklere bağlılık ve belirginliklerin değiştiği, ancak her birinin ulusal kimliğin inşasından kaynaklandığı ve bu süreç içinde yer aldığı bir durumdur. Kimlik, aktörlerin toplu olarak kendileri ve 
birbirleri hakkında sahip oldukları teorilere dayanan, aktörün doğası gereği sosyal bir tanımıdır" (Wendt, 1992).

Ontolojik güvenlik kavramı, Laing (2010)'in psikanalitik yaklaşımından doğarak Giddens'ın (1991) sosyolojik yaklaşımına kadar uzanmış ve 1990'lı yılların sonları itibari ile de uluslararası ilişkiler disiplininin ilgi alanına girmiş̧ir. Ontolojik güvenlik, fiziksel güvenlikten farklı olarak, kişinin kim olduğuna dair, eylemi ve seçimi mümkün kılan ve motive eden öznel duygusuna dayanan benliğin ya da kimliğin güvenliği olarak tanımlanabilir (Laing, 2010). Ontolojik güvenlik araştırmalarının tümünün devlet mekanizmasının kararlarını incelediğini söylemek mümkün değildir. Bir kısım araştırmacı, analiz düzeyi olarak bireyi alarak bireyin ontolojik güvenlik ihtiyacı olduğunu ve güvenlik arayışı içerisinde bulunduğunu savunmakta ve devlet mekanizmasının, kendi vatandaşlarının ontolojik güvenliklerinden sorumlu aktör olarak, onların toplumsal ontolojik güvenlik ihtiyaçlarını gidermek için dış politika kararlarını belirlediğini vurgulamaktadır. Bir diğer grup araştırmacı ise, devleti birey gibi değerlendirerek devletlerin güvenlik araması yaklaşımını fiziksel ve ontolojik güvenlik arayışı olarak ayırarak değerlendirmektedir (Rumelili, 2013). Mitzen (2006)'e göre, ontolojik güvenlik arayışında olan birim her ne olursa olsun, araştırmacılar, analiz düzeyinde yer alan birimin ontolojik güvenlik ihtiyacının devlet düzeyinde oluşan süreçleri, yapılan seçimlerin ve ortaya çıkan sonuçların nasıl yönlendirileceği üzerine düşünmektedir.

Ontolojik güvenlik kavramı, insanın psiko-sosyal ihtiyaçlarını güç ve eylem dinamikleriyle bir araya getiren psikolojik iyilik hali üzerine düşünmesini sağlar. Bir bireyin kimliği, sosyal yapılar da dahil olmak üzere, eylemler ve diğer bireylerle olan ilişkileri aracilığıyla meydana gelen ve devam ettirilen bir sosyal yapı olarak olarak algılanır. Buradan yola çıkarak, ontolojik güvenlik olgusunun arkasında yer alan sezgi, bütün sosyal aktörlerin faillik duygusuna sahip olmak ve onu gerçekleştirebilmek için istikrarlı bir benlik hissine sahip olma ihtiyacıdır. İnsan kendisini zaman içinde bütün ve sürekli bir varlık olarak algılamalıdır. Giddens'a göre, ontolojik güvenlik "çoğu insanın kendi öz kimliklerinin sürekliliğine ve onu çevreleyen sosyal ve maddi eylem ortamlarının sabit oluşuna duyduğu güvendir" (Giddens, 1991). Bu söylemden yola çıkarak ontolojik güvenliğin istikrar hissini ifade ettiğini söylemek mümkündür. Kimliğin sabit olduğu hissedildiğinde ontolojik olarak güvende olunduğu algısı oluşur (Kinnvall, 2007; Browning ve Joenniemi, 2016).

Mitzen (2006) ve Steele (2008), 'ontolojik güvenlik' olarak tanımladıkları şeyi birleştirmek için yapısalcı teoriyi daha da geliştirdiler. Bir başka deyişle, ontolojik güvenlik, bir aktörün güvenli ve sürekli bir kimlik deneyimleme ihtiyacını ifade eder. Mitzen (2006) tarafindan geliştirilen teori, ontolojik güvenliğin zaman içinde devletler ve onların önemli diğer aktörler arasındaki ilişkilerinin rutinleştirilmesi yoluyla kazanıldığını, bunun da devletlerin nasıl hareket edeceklerini ve karşı1lı̆̆nda hangi eylemleri bekleyeceklerini tahmin etmelerine izin verdiğini varsaymaktadır. Devletler, ontolojik olarak güvensiz hale gelmek yerine bu rutin davranışı sürdürmeye çalışacak, bu da kendisinin ve başkalarının eylemlerine dair alışılmadık beklentilerle sonuçlanacaktır. Bu tür bir aşinalık, amaçları araçlarla ilişkilendirmede yetersizlik ile sonuçlanır ve ontolojik olarak güvensizlik durumu devletin çıkarlarını nasıl sürdüreceği konusunda belirsiz bırakır. Ontolojik güvensizliği hafifletmek için bir devletin sergilediği davranış eğer kendi kimliğine ilişkin anlayışını pekiştiriyorsa, devlet kendi fiziksel güvenliğine zarar veren bir davranış sergileyebilir (Mitzen, 2006).

Ontolojik güvenlik kavramı, rutin ve benlik duygusunun düzenlendiği söylemlerde ortaya çıkar. Bu durum, sosyal ve maddi yapılar ile içselleşildiği varsayımına dayanır. Rutinler ve özanlatılar refahın sağlanması için önemli bir yere sahip olduğundan, rutinler ve özanlatılar ile duygusal bağ kurulur ve istikrarsızlaşma düşüncesi oluştuğunda derin bir endişe ortaya çıkar. İstikrarlı durum tehdit altında olduğunda ontolojik güvenlik fark edilir. İçinde yaşanılan sosyal ve fiziksel dünyanın güven veren yönleri tehdit altında olursa, rutinler sürdürülemezse ya da söylemler sorgulanırsa, kim olduğunu bilememe düşüncesi ortaya çıkar. Bunun sonucunda, rutinler yeniden devam ettirilerek ya da daha rahat söylemlere başvurularak güvenlik arayışına girilir (Giddens, 1991). Bu bağlamda değerlendirildiğinde ontolojik güvenlik arayışı, bahse konu aktöre kim olduğunu hatırlatan ve benliğini yeniden üreten eylemlere bilinçli olarak katılmak olarak nitelenebilir (Mitzen, 2006). Bu yönüyle, ontolojik güvenlik arayışı, devlet mekanizmasının seçimlerine yol gösteren sürekli ve kasıtlı bir arayış olarak görülen fiziksel güvenlik arayışından farklıdır.

Eylem, bireyin diğerleriyle rutin etkileşimler yoluyla zaman içinde oluşan kimliğinden doğar. Bireyler, faillik icra edebilmek için öz kimliklerinde istikrar ve sürekliliğe ihtiyaç duyarlar (Zarakol, 2010). 
Jennifer Mitzen (2006), devletlerin, uluslararası sistemde benlik ve faillik güvenliğini sağlamak için, ister işbirliğine dayalı ister çatışmaya dayalı olsun, diğer taraflarla rutinleştirilmiş ilişkilere ihtiyaç duyan ontolojik güvenlik arayan aktörler olduğunu vurgulamaktadır. Mitzen (2006), devletlerin güvenlik arayışında oldukları varsayımından hareket ederek "Dış politika sonuçları, ontolojik güvenlik perspektifinden bakıldığında, uluslararası ilişkilerin geleneksel devlet çıkarları bakış açısından tahmin edilebilecek sonuçlardan nasıl sapmaktadır?" ve "dış politikayı ontolojik güvenlik talepleriyle birlikte daha karmaşık duruma getirme süreci nasıl oluşmaktadır?" sorularını sorar ve devletlerin güvenlik arayışlarının geleneksel uluslararası ilişkiler analizlerinin öngördüğünden daha yönlü olduğunu savlar. Temel olarak yapılan güvenlik çalışmalarında araştırmacılar, güvenlik arayışını, şiddeti savuşturmayı ve siyasi yapının bütünlügünü korumayı amaçlayan maddi ya da fiziksel güvenlik kavramına atıfta bulunmaktadır (Bukh, 2015). Devletin fiziksel güvenliğinden bahsedildiğinde, devletin sınırlarının ve kurumlarının bütünlügünün korunmasıyla birlikte halkın yaşam güvenliğinin sağlanması da algılanmaktadır. Ontolojik güvenlik ise maddi güvenlikten farklı olarak, benliğin ya da öznelliğin güvenliği olarak tanımlanmaktadır (Mitzen, 2006). Ayrıca, devletlerin ontolojik güvenlik arayışı içinde olduklarını varsaymak, zaman içinde farklı karar vericilerin neden benzer davranışlar sergilediklerini anlamak için sosyolojik bir temel sağlar.

Temel bir ihtiyaç olarak değerlendirilen ontolojik güvenlik, aktörlerin kimliklerine algıladıkları tehdit dolayısıyla yaşadıkları belirsizlik durumundan korkmaları önermesine dayanır. Yaşanabilecek bu tarz bir belirsizlik, eylem-kimlik ilişkisini bozarak benlik olgusunu sürdürmeyi güçleştiren eylemde bulunmayı sekteye uğratabilir. Ontolojik güvensizlik, hangi tehlikelerle yüzleşileceğini ve hangilerinin gözardı edileceğini bilememenin acizliğini ifade eder. Ontolojik güvensizlik durumunda, birey enerjisini hayatta kalabilmek için acil ihtiyaçları için harcar. Ontolojik güvenlik ise, bireyin, sosyal yaşantısını yöneten araç-sonuç ilişkisiyle ilgili, kendinden emin beklentileri olduğu zaman oluşan durum olarak nitelenebilir. Ontolojik güvenliğini sağlamış bir aktör, nasıl hareket edeceğini ve nasıl kendisi olacağını gayet iyi bilir (Mitzen ve Larson, 2017).

Steele ise, ontolojik güvenliğin temelini oluşturan şeyin, başka devletlerle olan etkileşimden türetilmekten ziyade, bir devletin 'biyografik anlatısı' ile kimliğin arasındaki ilişkiden kaynaklandığını savunmaktadır. Biyografik anlat, bir devletin bir olaya anlam ve alaka verdiği hikayeleri veya gerekçeleri oluşturur (Steele, 2008: 10) ve bir devletin kendi davranışını refleksif olarak takip ederek inşa edilir. Ontolojik güvensizlik, "bu biyografik anlatı ile öz-kimlik arasında çok fazla mesafe olduğunda" ortaya çıkar ve ikisini yeniden hizalamaya çalışacak davranışın üretilmesini sağlar. $\mathrm{Bu}$ anlat, "eyleyenin eylemlerinin kaynağının 'ne' olduğunu refleksif olarak karakterize ettiği hatırlama biçimlerinin toplamını" (Steele, 2008) ve "eyleyenlerin kendi eylemlerini uyguladıkları sosyal ortamları anlamalarını ve bu ortamlarda benliklerini yerleştirmeye çalıştıkları yeri" (Steele 2008) içerir. Steele'e göre, ontolojik güvensizlik hem diğer Devletlerle olan etkileşimler yoluyla hem de "ontolojik güvenlik arama sürecinden kaynaklanan iç diyalektikten" temellenen ulusal kimliğe yönelik içsel değişiklikler yoluyla ortaya çıkabilir. Bu nedenle, ulusal kimliğin yalnızca Devletin başkalarıyla ilişkili olarak tanımlanması olarak değil, aynı zamanda Devletin benliğinin içsel olarak anlaşılması ve bunun sonucunda ortaya çıkan (Ben ve Öteki'nin) davranış beklentileri olarak anlaşılması gerekir (Steele 2008).

\section{3. Çin'in Ontolojik Güvenlik Algısı}

Ontolojik Güvenliğin temel unsurları, her biri kimliğin yaratılmasını etkileyen temel güven, rutinleştirilmiş davranış ve anlatılan benliği içerir. Temel güven sistemi, Ontolojik Güvenlik'in hem bireysel hem de uluslararası düzeyde kavramsallaştırılması için hayati öneme sahiptir. Temel güven, bireylerin ve devletlerin alış1lmadık koşullara yanıt vermesini sağlar. Temel güven sistemleri, eğer sağlıklıysa, yeni deneyimlerin ve davranışların bireyin dünya anlayışına entegre edilmesine izin verir (Giddens, 1991). Devletlerin, diğer devletlerin yeni politik yaklaşımlarını dikkate almalarına ve uygulamalarına izin veren benzer bir temel güven sistemi bulunmaktadır (Mitzen, 2006). Aynı zamanda var olan bu güven sistemi devlete uluslararası ilişkilerde yeni koşullara uyum sağlama kapasitesini arttırır. Çin'in sahip olduğu temel güvenlik sistemi ve rutin davranışlarını anlayabilmek için ulusal kimliğini oluşturan tarihsel koşulları 'Çin İstisnacıllğı' bağlamında değerlendirmek önemlidir.

Çin'in ontolojik güvenlik algısını değerlendirmek adına Zhang'ın 'Çin İstisnacılığı' ile ilgili yapmış olduğu üç farklı tarihsel tezahürü değerlendirmek bu minvalde önem arz etmektedir (Zhang, 2011). 
Zhang, Çin İmparatorluğu, Devrimci Çin Halk Cumhuriyeti ve Çağdaş Çin Hak Cumhuriyeti olarak sınıflandırma yaparak Çin'in ulus kimliğini ve Çin İstisnacılığı kavramını analiz etmektedir. İmparatorluk dönemini merkezilik, yardımsever barış yanlısı ve yüce kapsayıcılık, Devrimci Halk Cumhuriyeti dönemini büyük güç olgusu ve ahlakçılık, çağdaş dönemi ise reformist büyük güç, yardımsever barış yanlısı ve uyumlu kapsayıcılık özellikleriyle betimler (Zhang, 2011). Zhang'in yaptığı analizde, iki önemli yön bulunmaktadır. Bunlardan ilki, Çin'in 'merkezi' ya da 'Orta Krallık' olarak adlandırılan dünyanın ahlaki ve kültürel olarak üstün 'merkezi' olarak tanımlanmasıdır. Çin'in tarihsel olarak sahip olduğu kimlik, çağdaş ulusal kimliğinin en önemli parçasını oluşturmaktadır. Sahip olunan bu kimlik, askeri ve ahlaki açıdan üstün bir ülke - üstün bir lider ve Çin'e hakettiği saygının diğer devletler tarafindan gösterilmesi olarak tezahür etmektedir. Çin, ontolojik olarak kendisini dünyanın merkezine konumlayarak tarihsel bir üstün kimlik algısına sahiptir.

'Çin İstisnacılığı'na dayalı yapılan analizlerin dışında Zhang'in de belirttiği gibi Çin'de yaşanan travmatik tarihsel olayların etkisi de yadsınamaz birer gerçektir. 1839 yılında Birleşik Krallık'la yapılan Afyon Savaşları ile başlayan 1949'da Çin Halk Cumhuriyeti'nin kurulmasıyla sona eren Çin'in sahip olduğu gücün düşüş içerisinde bulunduğu 'aşağılama yüzyllı' Çin'in ulusal kimliğinin oluşmasında çok önemli bir tarihsel süreçtir (Zhang, 2011). 20 yüzyılın başlanı itibarıyla emperyalist devletler ve yozlaşmış yerel elitler eliyle Çin'in bölünme ve sömürülme sürecinin neticesinde Çin ulusal kimliğini etkileyen önemli sonuçlar oluşmuştur. Emperyalist devletlerin Çin üzerinde hakimiyet kurarak sömürü politikası izlemeleri gibi travmatik bir dönemi yaşamış olması, ilerleyen dönemlerde Çin'in dış politika oluşturma ve kalkınma süreçlerinde belirlediği stratejilerde adalet ve eşitlik gibi kavramların değişilmez ilkeler olarak benimsenmesi ve ahlaki açıdan üstün bir ulus olarak kimliğinin oluşmasına önemli katkıda bulunmuştur.

Çin'in kimlik algısına dayalı ontolojik güvenlik arayışları ile ilgili olarak dönem dönem değişen tutumu birçok araştırmacı tarafından analiz edilmiştir. Algılanan kimlik ile Çin'in ontolojik olarak güvensiz duruma gelme olasılığına karşı, diğer devletlere kıyasla sahip olduğu farklılıklar ortaya çıktıkça Çin'in eylemlerinin değiştiği ve güvenli bir benlik duygusunu sürdürme zeminine sahip olduğu söylenebilir. Soğuk Savaş'ın ardından Çin'in yenilenmiş bir büyük güç olarak dünya sahnesine çıkması ile birlikte Çin kimliği, büyük bir güç olarak yeniden küresel siyasete önemli bir aktör olarak katıldı. Çin ülkeler arasında karşılıklı fayda sağlayan bir büyüme modelini benimseyerek, kendisini tarihsel olarak batılı devletlerden ayıran özelliklere dayalı, yeni düzen sağlayıcı büyük bir güç olarak tanımlamaya başladı. Buna bağlı olarak ortaya çıan bu yeni durumda, Çin'i askeri güç üzerine inşa edilmiş bir ulus olarak değil yeni dönemde benzersiz niteliklere sahip bir bilgi üreticisi devlet olarak değerlendirmek önemlidir. Yapılan bu kavramsallaştırmada Çin'in dış politikasını yaşadığı tarihsel zorluklardan yola çıkarak çatışmaları, son çare olarak değerlendireceği fikrinin bilinç altında yatan düşünce olduğu söylenebilir. Bir diğer düşünce ise uyumlu kapsayıcılık ya da farklılıklarla uyum içerisinde olma kavramlarının, Çin'in uluslararası toplumla daha fazla bütünleşmesini vurgulamasıdır. Çin'in aralıksız süren ekonomik genişlemesi ve teknolojik atılımları yükselen ulusal kimlik kavramsallaştırması ile birlikte daha uyumlu bir hale geldi. 90'ların ortaları itibarıyla şimdiye kadar bahsedilen özellikleri bağlamında değerlendirilen Çin'in kimlik algısı, 21. yüzyılda kendisini yeni bir güvenlik politikası içerisinde bulmuştur.

Bahse konu yeni güvenlik algısının gelişimi, temel olarak Çin'in ulusal kimlik meselesi ile doğrudan bağlantılı olarak değerlendirilmiş ve bu durum önemli politik süreçlerde baskın faktör olarak ortaya çıkmıştır. Bu minvalde uluslararası toplumdan izole edilmiş yalnızlaşmış bir Çin algısının yerine, önemli bir güç olarak uluslararası topluma güçlü şekilde entegre olmuş bir Çin algısı yerleşmiştir. Zhang'a göre Çin'in güvenlik algısının ve belirlediği politikaların asıl amacı dünya barışını korumak ve ortak kalkınmayı teşvik etmektir. Bu bağlamda asya kıtasının doğal lideri olarak Çin ulusal kimliğinin meydana gelişi, Rozman'ın da belirttiği üzere dünya düzenine barışçıl bir şekilde dahil olma çabasına dayalıdır. Batının küresel siyaseti belirleyen merkezi bir konumda yer alması, Çin'in siyasi sisteminin değerlerini ve ideolojisini değiştirmesi gerektiği anlamına gelmektedir (Rozman, 2011). Çin'in sahip olduğu güvenlik algısında yaşanan bu değişimin, sahip olduğu baskın kimlikle çatışması Çin'in ontolojik güvenlik arayışı davranışı sergilemesi ile ilgili olarak önemli bir göstergedir. Burada Çin'in eylemleri ile ilgili olarak ortaya çıkan fikirsel anlatı bağlamında ihtilaf içerisinde bulunduğu devletlere yönelik eylemlerinin uzlaşmacı bir yöne doğru evrildiğini söylemek mümkündür. 


\section{Yapay Zekâ Teknolojisi ve Çin'in Ontolojik Güvenlik Algısı}

Çin'in sahip olduğu kimlikle ilişkili olarak, büyük bir kara parçası üzerinde hakimiyet sağlamak, sahip olduğu büyük nüfusu beslemek ve kontrol etmek ve tarihsel düşmanlara karşı ülke güvenliğini sağlamak öncelikli hedefleri olmuştur. Bununla birlikte köklerinden gelen büyük güç olma arzusu 1949 yılında komünist devrimle kurulan yeni devletin de itici güçlerinden olmuştur. Çin için büyük güç olma arzusunu gerçekleştirebilmek adına ekonomik ve askeri kapasiteyi arttırmak en önemli faktörler ola gelmiştir. Bu bağlamda, bilim ve teknoloji Çin'in stratejik hedeflerine ulaşmasında temel etken olarak değerlendirilmiştir.

Çin'in Batı'dan algıladığı güvensizlik ve bölgesel güç mücadelesinde hakim konumda olma çabası, teknolojik üstünlüğü elde edebilmek adına toplum nezdinde bir seferberlik politikası bağlamında yürütülmüştür. Mao döneminde başlayan kalkınma seferberliğine yönelik teknoloji başta olmak üzere birçok alanda kapasite arttırıcı faaliyetlerde bulunulmuştur. Bahse konu girişimler Deng Xiaoping döneminde de 'Reform ve Açılım' politikası ile birlikte artarak devam etmiştir (Wu, 2001). Soğuk Savaş'ın sona ermesiyle birlikte ABD'nin küresel siyasette baskın güç oluşu ve dünya düzeninin tek kutupluluğa doğru evrilişi Çin gibi tarihsel olarak büyük güç olma hedefine sahip bir devlet için bir güvenlik riski oluşturmaktadır. 21. yüzyıl itibariyle hem ekonomik hem askeri hem de teknolojik kapasitesini oldukça arttıran Çin'in hızlı yükselişi, uluslararası düzende yeni dengelerin oluşması adına önemli bir sürece girildiğinin habercisi oldu.

2000'li yılların başlarından itibaren yapay zekâ teknolojisine artan ilgi; derin öğrenme, makine öğrenmesi gibi yeni tekniklerin kullanılmaya başlanması; devlet, özel sektör ve akademik camia ile beraber toplumsal düzeyde ilginin de artışıyla birlikte yapay zekâ stratejisi stratejik bir konuma gelmiştir (Ermağan, 2021). 50'den fazla devletin yapay zekâ stratejsi belirlediği bu süreçte Çin, küresel anlamda yapay zekâ liderliğini elde etmeyi ontolojik güvenlik algısıyla hareket ederek hedeflemiştir. ABD ile birçok alanda giriştiği rekabet, teritoryal olarak ABD tarafindan çevrelendiği hissiyle birlikte değerlendirildiğinde, stratejik olarak yapay zekâ teknolojisinde ilk yapan olma, lider ülke olma avantaj1 ve markalaşmanın Çin için hayati bir öneme sahip olduğunu söylemek mümkündür.

2016 yılında Google DeepMind ekibi tarafından geliştirilen AlphaGo adlı yapay zekâ programının Go oyununda Koreli dünya şampiyonu Lee Sedol'ü yenmesi dünya çapında etki yarattı ve yapay zekâ teknolojisine olan kamuoyu ilgisini dikkat çekici düzeyde arttırdı (Boroweic, 2016). Söz konusu olay her ne kadar Batılı ülkelerde de önemli bir ilgi artışı yaratsa da asıl etkiyi Çin üzerinde yarattı. Bu olayı Çinli hükümet yetkilileri bir 'Sputnik Anı' olarak nitelendirdi (Lee, 2018). Çin'de yapay zekâ çalışmaları AlphaGo'nun bu tarihi başarısından sonra farklı bir boyuta geldi. 2017 yılı itibariyle 'Yeni Nesil Yapay Zekâ Geliştirme Planı'nın ( State Council, 2017) yayınlanması Çin'in yapay zekâ teknolojisi ile ilgili stratejik bir konum belirlediğinin en önemli göstergesi oldu. Uluslararası rekabet, ekonomik büyüme ve sosyal yönetişim alanlarına odaklanan 'Yeni Nesil Yapay Zekâ Geliştirme Planı' Çin'in stratejik olarak küresel rekabette söz sahibi olmasını sağlayacak bir dönüşüm politikası olarak değerlendirilebilir. Belirlenen plana göre, 2020 yılına kadar Çin, diğer büyük güçlerle rekabet gücünü korumayı ve yapay zekâ geliştirme ortamını optimize etmeyi, 2025 yılına kadar, temel yapay zekâ teorisinde 'büyük bir atılım' elde etmeyi ve bazı uygulamalarda dünya lideri olmayı ve son olarak 2030'a kadar, yapay zekâ için dünyanın inovasyon merkezi olmayı hedeflemektedir ( State Council, 2017). Çin'in bu stratejik yönelimi, ilk yapan olma ve yapay zekâ liderliği gibi önemli tanımlamaları elde etmek adına itici bir güç olarak görülebilir.

Yeni Nesil Yapay Zekâ Geliştirme Planı'nda, yapay zekânın uluslararası rekabetin yeni bir odak noktası haline geldiği ve "yapay zekânın geliştirilmesinin ... ulusal rekabet gücünü artırmak ve ulusal güvenliği korumak için önemli bir strateji olduğu" belirtilmektedir (State Council, 2017). Çin'in, askeri kapasitesinde sıçrama gerçekleştirebilmesi için yapay zekânın sunduğu stratejik firsatları kullanması gerektiğini vurgulanmaktadır. Çin, geleneksel silah teknolojisinde ABD'yi geçmek yerine, yapay zekâ temelli askeri teknolojilerde radikal atılımlar yapmayı ABD'yi geçmek için bir firsat olarak görmektedir. Çin'in askeri stratejisinde, ABD hegemonyasına meydan okumak için teknolojik kapasiteyi kullanma girişimleri 1990'ların sonlarından itibaren sürmektedir. Çin, ABD ile doğrudan rekabet etmek yerine, olası bir savaşta kritik bir avantaj ve barış zamanında güvenilir bir caydırıcılık sağlayabilecek asimetrik yetenekler geliştirmeye çalışmaktadır (Blasko, 2011). Bu stratejiyle, savaşta inisiyatifi ele geçirmek için 
düşmanların zayıflıklarına karşı alışılmışın dışında teknolojileri kullanmayı amaçlanmaktadır (Peng ve Yao, 2005).

Çin için stratejik öneme sahip teknolojik alanların güçlendirilmesi 2025'e kadar kritik bir önceliğe sahiptir. Devletin stratejik silah teknolojisi geliştirmek gibi belirli hedeflere ulaşmak için ulusal kaynakları harekete geçirmesi olarak tanımlanan 'bütün ulus (juguo tizhi)' sistemini hayata geçirmesi, Çin'in çekirdek teknolojilerde atılım yapma konusunda sahip olduğu isteği göstermektedir (Hu ve Jefferson, 2008). Bu bağlamda 'Bilim ve Teknoloji Yoluyla Çin'i Geliştirme Eylemleri' adlı planın hazırlanması Çin'in yapay zekâ başta olmak üzere bir çok teknolojik alanda öncü ülke olma yolundaki kararlılığını perçinlemektedir. Hazırlanan plan çerçevesinde Çin'in sahip olduğu inovasyon sistemleri optimize edilip yeniden düzenlenmektedir. Bununla birlikte, 2025 yılına kadar yapay zekâ, kuantum bilgisi, fotonlar ve mikro-nano elektronik, ağ iletişimi, biyotıp ve modern enerji sistemleri gibi alanlarda bir dizi ulusal laboratuvar kurmayı hedeflemektedir (Kaja vd., 2021).

Şimdiye kadar bahsedilen kapsamlı stratejik plan ve eylemlerin dışında Çin'in ABD'yi geçme arzusu, Çinli siyasi ve askeri liderlerinin açıklamalarında da oldukça sık vurgulanmaktadır. Başkan Xi Jinping 2018'de yaptı̆̆ 1 bir açıklamada Çin'in bir sonraki teknolojik ve endüstriyel devrimde ülkenin geleceğini güvence altına almak için yapay zekâ geliştirmesi, kontrol etmesi ve kullanması gerektiğini söyledi (Xin ve Chi-yuk, 2018). 2021 yılında yaptığı bir başka açıklamada ise küresel ekonomide artan korumacılık, küresel tedarik zincirindeki hızlı değişiklikler ve Covid-19 pandemisinin ardından artan belirsizlikler nedeniyle Çin'in teknolojik darboğazlarla mücadele çabalarını hızlandırması ve yapay zekâ, yarı iletkenler, kuantum teknolojisi, yaşam bilimi ve enerji gibi kilit alanlarda atılımlar yapması gerektiğini söyledi (Feng, 2021). Xi Jinping yaptığı bir başka açıklamada "ülkenin bilim ve teknoloji söz konusu olduğunda kendi kendine yetme çabalarını hızlandırması gerektiğini”, Çin'in bilimsel ve teknolojik bağımsızlığının "ulusal kalkınma için stratejik bir hedef” olarak görülmesi gerektiğini vurguladı. Ayrıca "bilimsel ve teknolojik gelişme, küresel bilim ve teknoloji sınırlarını hedeflemeli, ana ekonomik savaş alanlarına hizmet etmeli, ülkenin önemli ihtiyaçlarını karşılamaya çalışmalı ve insanların yaşamına ve sağlığına fayda sağlamalıdır" dedi. Aynı zamanda, ülkenin bilim ve teknolojide küresel bir lider olma hedefini yineleyerek, Parti Merkez Komitesinin "bilim ve teknolojide bir dünya gücü inşa etme stratejik hedefini sıkıca kavradığını ve küresel teknolojik gelişme firsatlarını temel bir misyon olarak benimsediğini” söyledi (Houweling, 2021). Başkan Xi Jinping'in açıklamaları da ortaya koymaktadır ki, teknolojik gelişmeyi sürdürmek ve yapay zekâ teknolojisinde lider olmak, Çin'in ulusal güvenliğini sağlamak ve korumak adına önemli bir faktör olarak değerlendirilmektedir.

Başkan Xi'nin açıklamaları ile birlikte değerlendirildiğinde Çin'in, gelişmekte olan alanlarda kalıcı veya geniş teknolojik avantajlar elde ederek, Çinli firmaların ülke dışında tekel gücüne sahip olmalarını, küresel teknoloji standartlarını kendi çıkarları doğrultusunda şekillendirmelerini ve gelirlerini artıran, veri havuzlarını genişleten ölçek ekonomilerinin oluşmasını sağlamayı hedeflediğini söylemek mümkündür. Çin ayrıca yapay zekâ temelli ürünlerin, telekom ekipmanlarının, bulut ağlarının ya da dijital ödeme sistemlerinin yalnızca Çin yapımı diğer ekipmanlarla uyumlu olmasını sağlayarak, kalıcı bir teknolojik avantajı ticari bir avantaja dönüştürme çabasındadır. Söz konusu bu davranış teknik standartların ayrılmasıyla sonuçlanacaksa, Çin liderliğindeki bir standardizasyon birçok rakip ülkede gelecekte oluşabilecek ekonomik firsatları sınırlayıcı etki yaratma potansiyeline sahiptir. Burada Çin'in elde edeceği üstünlük, Çin'in ekonomik kalkınmasına katkı sağlayacağı ölçüde ulusal güvenliğini tesis etmede de önemli firsatlar sunmaktadır.

Yapılan tüm bu girişim ve söylemlerin temelinde Çin'in ontolojik güvenlik algısının bulunduğunu söylemek olasıdır. Ekonomik büyümeyi önceleyen bir politik yaklaşımı uzun süre devam ettirdikten sonra, özellikle teknolojik atılımların giderek artması ve dışa bağımlılığın giderek azalması, Çin'i uluslararası rekabette önemli bir pozisyona taşıdı. Çin'in birçok alanda rekabet içerisinde olduğu ABD'nin, hamlelerini öngörebildiği ölçüde ona göre pozisyon alarak stratejik davranış sergiliyor oluşu, yapay zekâ alanında da kendini göstermektedir. Bu tutum, Çin'in ontolojik güvenlik düşüncesiyle hareket ettiğini ve ABD'ye karşı hamle avantajı ve üstünlük elde edebilmek adına belirli politikalar oluşturduğunu göstermektedir. 


\section{Sonuç}

Tarihsel olarak, teknolojik ilerlemeler toplumların bilgi kapasitelerini artırdı ve teknolojik ilerlemelerin ekonomik faydaları zaman içinde yayıldı. Ancak günümüzde geliştirilmekte olan yeni nesil teknolojilerin toplum, devlet ve birey düzeyindeki etkileri, daha çarpıcı sonuçlar doğurmaktadır. Geçmişten günümüze otomobil, nükleer enerji, bilgisayar, yarı iletkenler ve akıllı telefonlar dahil olmak üzere bir çok teknolojik ürünün üretimi ülkeler arasında yayılarak daha rekabetçi bir ortam ve geniş bir pazar oluştu. Bununla birlikte, gelişmekte olan dijital çağda, ilk yapan olma avantajına sahip devletlerin, yapay zekâ ve kuantum hesaplama gibi alanlarda üstünlük sağlamaları, belirli pazarlara hızla hükmetmeleri ve uluslararası rekabeti kendi lehlerine olacak şekilde düzenlemeleri olasıdır.

Çin'in yapay zekâ teknolojisine çok boyutlu bir stratejik anlam yüklemesini, Steele'nin ortaya koyduğu gibi, bir devletin 'biyografik anlatısı' ile kimliği arasındaki ilişkiden kaynaklanan ontolojik güvenlik düşüncesiyle açıklamak mümkündür. Çin'in tarihsel olarak teknolojik gelişmeleri her daim önceleyen bir politika belirlemesi ve tarihsel süreçte yaşadığ 1 elim olayların ulusal kimliğini oluşturan yapılar üzerindeki etkileri de göz önüne alındığında yapay zekâ teknolojisinde ABD ile neden rekabet ettiğini oldukça açı biçimde göstermektedir. Çin, yapay zekâ liderliği hedefine ulaşmak için sergilediği tutumla, teknolojik üstünlüğe dayalı olarak ABD ile çok boyutlu bir rekabete girişerek ekonomik gücüyle birlikte ABD'ye karş1 stratejik avantaj elde etmeyi hedeflemektedir. Bununla birlikte, Çin'in sahip olduğu 'büyük ticaret ulusu' kimliğini güçlendirerek başta ABD olmak üzere diğer devletlerle olan rutin ilişkilerini geliştirerek ontolojik güvenlik arayışı davranışı sergilediğini söylemek mümkündür.

Çin, yapay zekânın gelişimi ve yönetimi konusundaki uluslararası tartışmada merkezi bir aktördür. Çin'in yapay zekâ politikalarının gelişimini şekillendiren iç ihtiyaçlarını, uluslararası arenadaki emellerini ve etik kaygılarını anlamak önemlidir. Bütün bunları sadece dışsal olarak Batılı bir perspektiften değil, aynı zamanda içsel olarak bir Çin perspektifinden anlamak da önemlidir. Çin'in kimlik algısına dayalı ontolojik güvenlik arayışları ile ilgili olarak sergilediği tutum, algıladığı kimlik ile ontolojik olarak güvensiz duruma gelme ihtimali göz önüne alındığında, diğerlerine nazaran sahip olduğu farklılıklar ortaya çıktıkça davranışlarının değiştiği ve güvenli bir benlik duygusuyla hareket ettiği düşünülmektedir. Son tahlilde yapılan analizler neticesinde, yapay zekâ teknolojisinde yaşanan küresel rekabetin başat aktörlerinden olarak Çin'in izlediği yol haritasının ulusal güvenlik arayışlarından kaynaklandığı anlaşılmaktadır. Tarihsel olarak sahip olduğu ulusal kimliğinden gelen güç ve algılamalar Çin'in yapay zekâ serüvenini ortaya koymaktadır.

\section{BEYANLAR}

Hakem Değerlendirmesi : Çıkar Çatışması Finansal Destek
Diş bağımsız.

Yazar tarafından çıkar çatışması bildirilmemiştir.

Yazar bu çalışma için finansal destek almadığını beyan etmiştir. 


\section{KAYNAKÇA}

Blasko, D. J. (2011). “' "Technology Determines Tactics': the relationship between technology and doctrine in Chinese military thinking“. J Strat Stud, 34(3), 355-381.

Borowiec, S. (2016). “Google's AI machine v world champion of 'Go': everything you need to know”. The Guardian. https://www.theguardian.com/technology/2016/mar/09/googles-ai-machine-v-worldchampion-of-go-everything-you-need-to-know (28.06.2021).

Browning, C. ve P. Joenniemi. (2016). “Ontological Security”. Self-articulation and the Securitization of Identity, Conflict and Cooperation, 52 (1), 31-47.

Bukh, A. (2015). "Shimane Prefecture, Tokyo and the territorial dispute over Dokdo/Takeshima: regional and national identities in Japan". The Pacific Review, 28(1), 47-70.

Callahan, W. A. (2012). "Sino-speak: Chinese Exceptionalism and the Politics of History". The Journal of Asian Studies, 71(1), 33-55.

Ermağan, İ. (2021). Worldwide Artificial Intelligence Studies with a Comparative Perspective: How Ready is Turkey for This Revolution? Artificial Intelligence Systems and the Internet of Things in the Digital Era, Proceedings of EAMMIS 2021. (Ed. Abdalmuttaleb M. A. Musleh Al-Sartawi, Anjum Razzaque ve Muhammad Mustafa Kamal). s. 500-512. Springer.

Feng, C. (2021). "Chinese President Xi Jinping seeks to rally country's scientists for 'unprecedented' contest". South China Morning Post. https://www.scmp.com/news/china/politics/article/3135328/chinesepresident-xi-jinping-seeks-rally-countrys-scientists (29.06.2021).

Giddens, A. (1991). Modernity and self-identity: Self and society in the late modern age. Stanford University Press.

Houweling, E. (2021). "Xi Jinping orders China to become more self-reliant in technology”. Verdlct. https://www.verdict.co.uk/xi-jinping-orders-china-to-become-more-self-reliant-in-technology/ (29.06.2021).

Hu, A. G. ve G. H. Jefferson. (2008). Science and technology in China. China's great economic transformation. (Ed. L. Brandt ve T. Rawski). s. 286-336. Cambridge: Cambridge University Press.

Kaja, A., S. Stein ve T. Xiang. (2021). “China's 14th Five-Year Plan (2021-2025): Signposts for Doing Business in China”. Global Policy Watch. https://www.globalpolicywatch.com/2021/04/chinas-14th-five-yearplan-2021-2025-signposts-for-doing-business-in-china/ (30.06.2021).

Kinnvall, C. (2007). Globalization and religious nationalism in India: The search for ontological security. Routledge.

Laing, R. (2010). The divided self: An existential study in sanity and madness. Penguin UK.

Lee K. F. (2018). AI superpowers: China, Silicon Valley, and the new world order. Boston: Houghton Mifin Harcourt.

Mitzen, J. (2006). “Ontological security in world politics: state identity and the security dilemma”. European Journal of International Relations, 12(3), 341-370.

Mitzen, J. ve K. Larson (2017). Ontological security and foreign policy. Oxford Research Encyclopedia of Politics. https://oxfordre.com/politics/view/10.1093/acrefore/9780190228637.001.0001/acrefore9780190228637-e-458 (28.06.2021).

Peng G. ve Y. Yao (Eds). (2005). The science of military strategy. Beijing: Military Science Publishing House.

Rozman, G. (2011). "Chinese national identity and its implications for international relations in East Asia". AsiaPacific Review, 18(1), 84-97.

Rumelili, B. (2013). Identity and desecuritization: The pitfalls of conflating ontological and physical security. Journal of International Relations and Development, 18(1), 52-74.

State Council. (2017). "Notice of the New Generation Artificial Intelligence Development Plan." http://www.gov.cn/zhengce/content/2017-07/20/content_5211996.htm. (30.06.2021).

Steele, Brent J. (2008). Ontological Security in International Relations: Self-identity and the IR State. Oxford: Routledge

Wendt, A. (1992). Anarchy is What States Make of it: The Social Construction of Power Politics. International Organization, 46(2), 391-425.

Wu, B. (2001). The Chinese Security Concept and its Historical Evolution. Journal of Contemporary China, 10(27), 275-283.

Xin, Z ve C. Chi-yuk. (2018). "Develop and control: Xi Jinping urges China to use artificial intelligence in race for tech future". South China Morning Post. https://www.scmp.com/economy/chinaeconomy/article/2171102/develop-and-control-xi-jinping-urges-china-use-artificial (1.07.2021).

Zarakol, A. (2010). Ontological (in) security and state denial of historical crimes: Turkey and Japan. International relations, 24(1), 3-23. 
Zhang, F. (2011). The Rise of Chinese Exceptionalism in International Relations. European Journal of International Relations, 19(2), 305-28. 